\title{
Dietary intake and body composition in HIV-positive and -negative South African women
}

\author{
Stephanie V Wrottesley ${ }^{1}$, Lisa K Micklesfield ${ }^{1}$, Matthew M Hamill ${ }^{1,2}$, Gail R Goldberg², \\ Ann Prentice ${ }^{2}$, John M Pettifor ${ }^{1}$, Shane A Norris ${ }^{1}$ and Alison B Feeley ${ }^{1, *}$ \\ ${ }^{1}$ MRC/Wits, Developmental Pathways for Health Research Unit (DPHRU), Faculty of Health Sciences, University \\ of the Witwatersrand Medical School, 7 York Road, Parktown 2193, Johannesburg, South Africa: ${ }^{2}$ MRC Human \\ Nutrition Research (HNR), Cambridge, UK
}

Submitted 20 December 2012: Final revision received 29 March 2013: Accepted 29 May 2013: First published online 9 July 2013

\begin{abstract}
Objective: The present paper examines dietary intake and body composition in antiretroviral (ARV)-naive HIV-positive compared with HIV-negative South African women, as well as the impact of disease severity on these variables.

Design: Baseline data from a longitudinal study assessing bone health in HIVnegative and HIV-positive premenopausal South African women over 18 years of age were used. Anthropometry and body composition, measured by dual energy X-ray absorptiometry, were analysed together with dietary intake data assessed using an interviewer-based quantitative FFQ.

Setting: Soweto, Johannesburg, South Africa.

Subjects: Black, urban South African women were divided into three groups: (i) HIV-negative ( $\mathrm{HIV}^{-}$; $n$ 98); (ii) HIV-positive with preserved CD4 counts ( $\mathrm{HIV}^{+}$ non-ARV; $n 74$ ); and (iii) HIV-positive with low CD4 counts and due to start ARV treatment $\left(\mathrm{HIV}^{+}\right.$pre-ARV; $\left.n 75\right)$.

Results: The prevalence of overweight and obesity was high in this population (59\%). The $\mathrm{HIV}^{+}$pre-ARV group was lighter and had a lower BMI than the other two groups (all $P<0 \cdot 001$ ). $\mathrm{HIV}^{+}$pre-ARV women also had lower fat and lean masses and percentage body fat than their $\mathrm{HIV}^{-}$and $\mathrm{HIV}^{+}$non-ARV counterparts. After adjustment, there were no differences in macronutrient intakes across study groups; however, fat and sugar intakes were high and consumption of predominantly refined food items was common overall.

Conclusion: HIV-associated immunosuppression may be a key determinant of body composition in HIV-positive women. However, in populations with high obesity prevalence, these differences become evident only at advanced stages of infection.
\end{abstract}

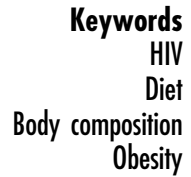

The introduction of antiretroviral (ARV) therapy has dramatically altered the morbidity profile of HIV-positive populations, with an increase in prevalence of noncommunicable disease risk factors such as overweight and obesity being observed ${ }^{(1,2)}$. This is of particular concern in South Africa where, among adults over 15 years of age, $17 \cdot 8 \%$ were estimated to be living with HIV in $2008^{(3)}$ and approximately $45 \%$ were found to be overweight or obese in the 2003 Demographic and Health Survey (SADHS $)^{(4)}$.

Although the public health impact of HIV and associated non-communicable disease risk is greatest in low- to middle-income countries, to date most studies have been conducted in high-income countries, on predominantly ARV-treated males with low $\mathrm{BMI}^{(5-8)}$. Lipodystrophy, a commonly recognized side-effect of certain ARV drugs, has been linked to visceral fat accumulation and metabolic disorders such as dyslipidaemia and glucose intolerance ${ }^{(9)}$. In black South African (SA) women, ARV-associated increases in BMI, fat mass, percentage body fat and waist circumference, but not in lean body mass or waist:hip ratio, have been shown ${ }^{(10)}$. This increase in fat, as well as the proposed tendency towards visceral rather than subcutaneous fat accumulation $^{(11)}$, must therefore be further explored in this population due to the potential long-term negative effects on disease risk and health ${ }^{(12)}$.

While the evidence for body composition changes associated with ARV drugs continues to grow, there is less research focusing on the effect of the HIV infection itself. Hadigan et al. ${ }^{(13)}$ found that, independent of ARV, HIVpositive women in the USA demonstrated a higher percentage body fat and truncal fat and lower percentage lean body mass than HIV-negative controls. In addition, other data suggest that HIV-positive patients with higher 
BMI, skinfold thicknesses and insulin concentrations prior to ARV initiation may be more likely to develop lipodystrophy over 2 years of ARV drug use ${ }^{(14)}$.

Although HIV-positive status has traditionally been associated with low energy intake, most likely as a result of reduced appetite ${ }^{(15)}$, SA data show energy intake in HIV-positive individuals to be equivalent to, or in excess of, that of their HIV-negative counterparts ${ }^{(16)}$. However, high total and saturated fat intakes, as well as low n-3 PUFA and fibre intakes, have also been reported in HIV-positive populations, which may indicate overall poor diet quality ${ }^{(16-19)}$. This suggests that HIV patients may be as affected by the global obesity epidemic as the wider population, and that poor diet quality may be a key factor in the increasing prevalence of overweight and obesity in HIV-positive populations. The majority of these studies, however, did not include HIV-negative control groups; thereby making the impact of HIV infection itself difficult to ascertain.

In the present paper we examine dietary intake and body composition (fat and lean tissue) in ARV-naïve HIV-positive and HIV-negative black urban SA women. In addition, we explore whether the relationships between HIV infection, body composition and dietary variables are influenced by differences in disease severity by comparing affected women with low and relatively preserved CD4 counts.

\section{Methods}

\section{Participants}

The present study was a baseline dietary intake and body composition analysis of HIV-negative and HIV-positive black women participating in a longitudinal assessment of bone health in urban South Africa. The aim was to recruit ninety-five $( \pm 5)$ HIV-negative and seventy-three $( \pm 10)$ in each of the two HIV-positive groups. This sample size was based on calculations for the longitudinal study to detect a $2 \%$ change in lumbar spine bone mineral density, allowing for a between-individual CV in bone mineral density of $5 \%$, with $95 \%$ confidence and $80 \%$ power. Inclusion criteria required women to be over 18 years of age; premenopausal; not pregnant or not planning to become pregnant for at least 12 months of the follow-up; and, if HIV positive, not yet using ARV and free from any current AIDS-related illness as defined by the WHO or the US Centers for Disease Control and Prevention. Two hundred and forty-seven women in total, HIV-positive $\left(\mathrm{HIV}^{+} ; n\right.$ 149) and HIV-negative $\left(\mathrm{HIV}^{-} ; n\right.$ 98), were recruited at Chris Hani Baragwanath Academic Hospital in Soweto, through contact with either the 'ZAZI' voluntary counselling and testing centre or the hospital's HIV clinic. Participants were divided as follows: (i) HIV-negative (group 1; $\mathrm{HIV}^{-}, n$ 98); (ii) HIV-positive with preserved CD4 counts $\left(\geq 350 \times 10^{6}\right.$ cells/l), not eligible for ARV therapy (group 2; $\mathrm{HIV}^{+}$non-ARV, $n$ 74); and (iii) HIV-positive with low CD4 counts $\left(\leq 200 \times 10^{6}\right.$ cells/1), eligible for ARV therapy and due to start ARV (group 3; $\mathrm{HIV}^{+}$ pre-ARV, $n$ 75).

\section{Antbropometry}

Weight was measured to the nearest $0 \cdot 1 \mathrm{~kg}$ using a digital scale (Scales 2000, Durban, South Africa) and height was measured to the nearest $1 \mathrm{~mm}$ using a wall-mounted stadiometer (Holtain, Crymych, UK) and with the participant's head in the Frankfort horizontal plane. These measurements were used to calculate the BMI (weight $(\mathrm{kg})$ divided by the square of height $\left(\mathrm{m}^{2}\right)$ ) of each participant. Underweight, normal weight, overweight and obese were defined as BMI $<18 \cdot 5 \mathrm{~kg} / \mathrm{m}^{2}$, BMI $=18 \cdot 5-24 \cdot 9 \mathrm{~kg} / \mathrm{m}^{2}$, $\mathrm{BMI}=25 \cdot 0-29 \cdot 9 \mathrm{~kg} / \mathrm{m}^{2}$ and $\mathrm{BMI} \geq 30 \cdot 0 \mathrm{~kg} / \mathrm{m}^{2}$, respectively. Waist circumference, taken approximately half-way between the iliac crest and the lowest rib, and hip circumference, taken at the maximum circumference around the hips, were measured using a non-stretchable measuring tape to the nearest $1 \mathrm{~cm}$. All measurements were carried out by trained investigators using standardised procedures and participants wore minimal clothing and no shoes while measurements were taken.

\section{Body composition}

Dual energy X-ray absorptiometry (DXA) scans were performed according to standard procedures using a Hologic QDR 4500A dual-energy X-ray absorptiometer (software version 12.5:7; Hologic Inc., Bedford, MA, USA). Whole-body fat and lean mass were analysed as whole body less head (WBLH) because many of the women wore wigs and hair weaves, which could have affected the DXA measurements in the head region. These data have been published by Hamill et $a l^{(20)}$. Trunk and limb (arms and legs) fat masses were derived from DXA scans. Percentage fat mass for WBLH, as well as for the trunk and limbs as percentages of WBLH fat mass, were calculated. To compare body fat distribution between the groups, trunk:limb fat mass was determined. Fat mass:lean mass ${ }^{2}$ was also calculated as this was shown to best describe the relationship between fat and lean mass in this population ${ }^{(20)}$.

\section{Dietary intake}

The dietary assessment tool used in the present study was an interviewer-conducted quantitative FFQ developed for use in South Africa. The questionnaire took on average 40 min to complete and included a total of 214 commonly eaten foods. These food items were derived from analyses of eleven dietary surveys conducted in rural and urban South Africa since 1983, and the list includes all foods eaten by at least $3 \%$ of the population ${ }^{(21)}$. The FFQ was extensively piloted on SA adolescents from the Birth to Twenty cohort at both 15 years (interviewing both adolescents and their primary caregivers, $\left.n 150^{(22)}\right)$ and 
17 years of age ( $n 1700$ (AB Feeley, unpublished results)), as well as on adult research assistants during training, and modified accordingly.

To cater for illiteracy in the SA population, the FFQ utilises food flash cards (high-quality photographs) of the food items ${ }^{(23)}$. Data were collected on the previous week's ( $7 \mathrm{~d}$ ) dietary intake, including convenience food products, in order to estimate habitual intake for each participant. Participants were asked to separate the food flash cards into a series of piles. First, they went through each food card and created a pile of food items they 'rarely/never' eat or drink. Thereafter, they went through the remaining food cards and created a pile of food items they eat/drink less frequently ('occasional'), and a pile they eat regularly and in the past $7 \mathrm{~d}$. The participant was then prompted for information on the frequency and amounts of the food items consumed regularly in her diet, the details of which were recorded on the FFQ. Portion sizes were estimated using household measures and a combination of two-dimensional life-size drawings of foods and utensils and three-dimensional food models as described and validated by Steyn et $a l^{(24)}$. Items eaten occasionally or rarely/never were also recorded.

Coding involved the conversion of the household measures (e.g. one cup/one serving spoon/one slice) to grams so that an average intake over the previous $7 \mathrm{~d}$ could be calculated. Nutrient composition (energy and macronutrients) was estimated using FoodFinder3, a nutrient analysis software program based on the SA Medical Research Council food composition tables ${ }^{(25)}$.

Quality control for dietary data acquisition was undertaken by extensive and repeated training of interviewers, reviewing the questionnaires for missing or spurious data, questioning participants on ambiguous answers and spotchecking questionnaires by a second interviewer (usually the senior nutritionist). The plausibility of the reported energy intake data was assessed according to study-specific cut-offs as described by Goldberg et al. $^{(26)}$ and Black ${ }^{(27)}$.

The US Dietary Reference Intakes ${ }^{(28)}$ for energy and macronutrients were selected for assessing the intakes of the study groups compared with recommendations, as these are most commonly used in South Africa and the most useful for comparison with other published data. Nutrient intakes were therefore compared with the Estimated Energy Requirement, the RDA for protein and carbohydrate and the Adequate Intake for fibre in adult women aged $19-50$ years. The median intakes for carbohydrate, protein and fat as proportions of total energy intake were calculated and compared with the Acceptable Macronutrient Distribution Ranges.

Variation in the food items consumed between study groups was assessed by comparing the twenty most commonly consumed items, as well as their respective food groups. The top twenty reported food items were ranked from the most to the least consumed according to the mean intake reported in grams per day.

\section{Socio-economic status and education}

Socio-economic status (SES) was assessed using an asset index similar to that used by McVeigh et al. ${ }^{(29)}$. This scored each participant according to the number of household assets she possessed out of a possible twelve (electricity, television, radio, motor vehicle, fridge, washing machine, telephone, video machine, microwave, MNET television channel, DSTV satellite television, cellular telephone). An asset score percentage was then calculated for each participant ((number of recorded household assets $/ 12) \times 100)$.

Level of education was assessed according to the number of years completed at primary, secondary or tertiary level.

\section{Etbics}

The study was approved by the University of the Witwatersrand Human Research Ethics Committee (HREC Number: M101525) and the Gauteng Department of Health. Individuals gave written consent prior to enrolment into the study.

\section{Statistical analysis}

Data were analysed using the statistical software package STATA $11 \cdot 0$. Where 'inaccurate reporters' were identified, dietary data were truncated using Goldberg cut-offs so that energy and macronutrient intakes represented the lowest or highest plausible intake for under- or over-reporters, respectively, according to body size. Continuous variables for participant characteristics, as well as anthropometric and body composition measurements and dietary intake, were not normally distributed and were therefore summarised using the median and interquartile range. Education level and BMI categories were summarised as percentage in each group. Continuous and categorical variables for participant characteristics were compared between the three study groups using the Kruskal-Wallis test for non-parametric data and the $\chi^{2}$ test, respectively. Age was found to be significantly different between groups; therefore all subsequent analyses were adjusted for age. Regression analyses were performed to compare differences in anthropometric and body composition variables between the $\mathrm{HIV}^{-}$group and the $\mathrm{HIV}^{+}$non-ARV and $\mathrm{HIV}^{+}$preARV groups combined. Between-group comparisons were then made using multiple linear regression models with dummy variables created to distinguish between the $\mathrm{HIV}^{+}$groups. These methods were repeated for analysis of dietary intake data; however, in addition to ageadjusted analyses, subsequent regression analyses were controlled for both age and total energy intake in order to adjust for the dietary variation attributed to differences in body size between groups. Finally, multiple regression models were used to explore whether any of the variables found to differ between groups were independent predictors of anthropometric and body composition 
differences. Where appropriate, hypotheses were conducted using Bonferonni-adjusted $\alpha$ levels of $0 \cdot 016$ per test $(0 \cdot 05 / 3)$.

\section{Results}

Table 1 summarises the participant characteristics and anthropometric variables for the three study groups (previously described, in part, by Hamill et al. ${ }^{(20)}$ ). The $\mathrm{HIV}^{+}$pre-ARV group had a significantly lower median CD 4 count $\left(175 \times 10^{6}\right.$ cells/l) than the $\mathrm{HIV}^{+}$non-ARV group $\left(420 \times 10^{6}\right.$ cells/1) as a result of the study design $(P<0 \cdot 001)$. Both SES score and level of education were similar across all groups. The $\mathrm{HIV}^{+}$pre-ARV group had significantly lower body weight, BMI and waist and hip circumference than the other groups (most $P<0 \cdot 001$ ). The prevalence of overweight and obesity was high in the whole sample, with $59 \%$ of women being overweight or obese. There was a significant difference in the distribution of participants across BMI categories between the groups, with the $\mathrm{HIV}^{+}$pre-ARV group having significantly fewer obese individuals (16\%) than both the $\mathrm{HIV}^{-}$(30\%; $P=0 \cdot 01)$ and $\mathrm{HIV}^{+}$non-ARV (37\%; $\left.P=0 \cdot 01\right)$ groups. The $\mathrm{HIV}^{+}$pre-ARV group also had a higher underweight prevalence $(11 \% ; P<0 \cdot 01)$, approximately three- and eleven-fold higher than the $\mathrm{HIV}^{-}$and $\mathrm{HIV}^{+}$non-ARV groups, respectively.

There was a significant difference in fat mass between the groups, with the $\mathrm{HIV}^{+}$pre-ARV group having lower total $(P<0 \cdot 001)$, trunk $(P<0 \cdot 001)$ and limb fat masses $(P<0 \cdot 001)$, and percentage body fat $(P<0 \cdot 001)$, than the other two groups (Table 2). However, when expressed as a percentage of whole-body fat mass, trunk and limb fat percentages were no longer different between the groups. The $\mathrm{HIV}^{+}$pre-ARV group had lower fat mass:lean mass ${ }^{2}$ than the other two groups; however, trunk:limb fat mass was not different between the groups. Correlations confirmed the relationship between CD4 count and fat mass $(r=0 \cdot 273 ; P=0 \cdot 019)$ and CD4 count and lean mass $(r=0 \cdot 299 ; P=0 \cdot 05)$.

Table 3 presents the results of multiple regression analyses for BMI, WBLH fat mass and lean mass, trunk fat mass and limb fat mass. Only the variables which contributed significantly to the models are presented. The overall models explain $14 \%$ of the variance in both BMI and WBLH fat mass, 34\% of the variance in WBLH lean mass and $13 \%$ of the variance in both trunk and limb fat masses. Age and being in the $\mathrm{HIV}^{+}$pre-ARV group significantly contributed to the models for BMI, WBLH fat mass and trunk fat mass (all $P<0 \cdot 001$ ), with $\mathrm{HIV}^{+}$preARV group status being associated with an approximately $4.5 \mathrm{~kg} / \mathrm{m}^{2}$ decrease in BMI, an $8 \mathrm{~kg}$ decrease in WBLH fat mass and a $3.5 \mathrm{~kg}$ decrease in trunk fat mass. Age, height and being in the $\mathrm{HIV}^{+}$pre-ARV group were significant contributors to the variation in both WBLH lean mass (all $P<0 \cdot 001)$ and limb fat mass $(P=0 \cdot 004, P=0 \cdot 042$ and $P<0 \cdot 001$, respectively), with an approximately $3 \mathrm{~kg}$ lower lean mass and $4 \mathrm{~kg}$ lower limb fat mass being associated with $\mathrm{HIV}^{+}$pre-ARV group status.

The daily energy and macronutrient intakes are presented in Table 4 . None of the components of dietary intake were different between $\mathrm{HIV}^{-}$and $\mathrm{HIV}^{+}$participants, with the exception of total protein and animal protein intakes which were significantly lower in the $\mathrm{HIV}^{-}$than the $\mathrm{HIV}^{+}$individuals $(P=0 \cdot 023$ and $P=0 \cdot 015$, respectively). However, when adjusted for total energy intake, the differences in total and animal protein intake were no longer significant. Between-group analyses similarly found no differences between $\mathrm{HIV}^{-}, \mathrm{HIV}^{+}$non$\mathrm{ARV}$ and $\mathrm{HIV}^{+}$pre-ARV groups in any of the dietary intake variables. Dietary intake exceeded the Estimated Energy Requirement, the RDA for carbohydrate and protein, as well as the Adequate Intake for fibre across all three study groups.

Carbohydrate, protein, fat and fibre accounted for approximately $54 \%, 11 \%, 30 \%$ and $4 \%$, respectively, of total energy intake across all three groups (data not shown). Intakes, as percentages of total energy intake, were therefore within the Acceptable Macronutrient Distribution Ranges for carbohydrate (45-65\%), protein (10-35\%) and fat $(20-35 \%)$ for all groups. Approximately $8 \%, 5 \%$ and $21 \%$ of participants in the sample had carbohydrate, fat and protein intakes, respectively, below the acceptable range, while $5 \%$ and $19 \%$ had carbohydrate and fat intakes, respectively, above the acceptable range. Alcohol accounted for less than $1 \%$ of total energy intake in all groups.

The twenty most commonly consumed food items and their respective food groups are shown in Table 5. Data are presented for the whole sample due to the lack of differences seen in the food items consumed between study groups. The $\mathrm{HIV}^{+}$pre-ARV group consumed the highest amount of food mass from the top twenty items $(1176 \mathrm{~g} / \mathrm{d})$ compared with the $\mathrm{HIV}^{-}$and $\mathrm{HIV}^{+}$non-ARV groups (929 and $1142 \mathrm{~g} / \mathrm{d}$, respectively). The most commonly consumed food item was maize meal (made into a stiff porridge/(pap') at a mean intake of $258 \mathrm{~g} / \mathrm{d}$. The most commonly recorded food group was cereal and cereal products (featured four times in the top twenty), with most cereal products being highly refined 'white carbohydrate'. Fruit and vegetables both featured twice; however, the vegetable component included French fries which are high in fat (usually sunflower oil). Sugar consumption was high overall, with granulated white sugar being the most frequently recorded food item in the sample (reported 533 times at an average of $15 \mathrm{~g} / \mathrm{d}$ ) and sweetened carbonated drinks being ranked second with a mean consumption of $197 \mathrm{~g} / \mathrm{d}$ and equating to approximately $340 \mathrm{~kJ}$ of energy daily. Meat and meat products featured three times in the top twenty food items; however, the cuts of meat tended to be highly processed and fried in sunflower oil (e.g. polony and 
Table 1 Participant characteristics and anthropometric variables according to study group: premenopausal black women, Soweto, Johannesburg, South Africa

\begin{tabular}{|c|c|c|c|c|c|c|c|c|c|}
\hline \multirow[b]{2}{*}{ Variable } & \multicolumn{2}{|c|}{$\begin{array}{l}\operatorname{HIV}^{-}(n 98) \\
\quad(1)\end{array}$} & \multicolumn{2}{|c|}{$\begin{array}{l}\mathrm{HIV}^{+} \text {non-ARV }(n 74) \\
(2)\end{array}$} & \multicolumn{2}{|c|}{$\begin{array}{l}\mathrm{HIV}^{+} \text {pre-ARV }(n 75) \\
\text { (3) }\end{array}$} & \multirow[b]{2}{*}{$P^{*}, \mathrm{HIV}^{-} v . \mathrm{HIV}^{+}$} & \multirow{2}{*}{$\begin{array}{l}\text { Between-group } \\
\text { comparison }\end{array}$} & \multirow[b]{2}{*}{$P^{\star}$} \\
\hline & Median & IQR & Median & IQR & Median & IQR & & & \\
\hline Age (years) & 28 & $23-37$ & 33 & $29-37$ & 33 & 28-39 & $<0.001 t$ & $\begin{array}{l}\text { (1) v. (2) } \\
(1) v .(3) \\
(2) v .(3)\end{array}$ & $\begin{array}{c}<0.001 \\
<0.002 \\
0.92\end{array}$ \\
\hline $\begin{array}{l}\text { Current CD4 count }\left(\times 10^{6} \text { cells } / \mathrm{l}\right) \\
\text { SES }(n 217)\end{array}$ & ND & - & 420 & $345-472$ & 175 & $105-226$ & NA & (2) v. (3) & $<0.001$ \\
\hline \multicolumn{10}{|l|}{ Education (\%) (n 220) } \\
\hline Primary & $2 \cdot 4$ & - & $4 \cdot 1$ & - & $6 \cdot 1$ & - & & & \\
\hline Secondary & 91.5 & - & $93 \cdot 2$ & - & $90 \cdot 8$ & - & $0 \cdot 206 \ddagger$ & & \\
\hline Tertiary & $6 \cdot 1$ & - & $2 \cdot 7$ & - & $3 \cdot 1$ & - & & & \\
\hline \multicolumn{10}{|l|}{ Anthropometry } \\
\hline Weight (kg) & $67 \cdot 1$ & $56 \cdot 8-78 \cdot 3$ & $69 \cdot 75$ & $59 \cdot 6-82 \cdot 8$ & $61 \cdot 4$ & $50 \cdot 9-68 \cdot 6$ & 0.033 & $\begin{array}{l}\text { (1) v. (2) } \\
\text { (1) v. (3) } \\
\text { (2) v. (3) }\end{array}$ & $\begin{array}{r}0.945 \\
<0.001 \\
<0.001\end{array}$ \\
\hline Height (m) & $1 \cdot 58$ & $1 \cdot 54-1 \cdot 62$ & $1 \cdot 59$ & $1 \cdot 56-1 \cdot 62$ & $1 \cdot 59$ & $1 \cdot 55-1 \cdot 63$ & 0.015 & $\begin{array}{l}\text { (1) } v .(2) \\
\text { (1) } v .(3) \\
\text { (2) } v .(3)\end{array}$ & $\begin{array}{l}0.029 \\
0.05 \\
0.822\end{array}$ \\
\hline BMI $\left(\mathrm{kg} / \mathrm{m}^{2}\right)$ & $27 \cdot 3$ & $23 \cdot 1-31 \cdot 7$ & $27 \cdot 8$ & $23 \cdot 3-32 \cdot 3$ & $23 \cdot 5$ & $20 \cdot 4-27 \cdot 0$ & $<0.002$ & $\begin{array}{l}\text { (1) } v .(2) \\
\text { (1) } v .(3) \\
\text { (2) } v .(3)\end{array}$ & $\begin{array}{r}0.479 \\
<0.001 \\
<0.001\end{array}$ \\
\hline Overweight (\%) & 35 & - & 28 & - & 28 & - & & & \\
\hline Obese (\%) & 30 & - & 37 & - & 16 & - & $<0.01 \ddagger$ & & \\
\hline Underweight (\%) & 4 & - & 1 & - & 11 & - & & & \\
\hline Waist circumference $(\mathrm{cm})$ & 86 & $76-94$ & 86 & $79-99$ & 81 & $73-88$ & 0.251 & $\begin{array}{l}\text { (1) v. (2) } \\
\text { (1) v. (3) } \\
\text { (2) v. (3) }\end{array}$ & $\begin{array}{r}0.517 \\
0.009 \\
<0.002\end{array}$ \\
\hline Hip circumference $(\mathrm{cm})$ & $106 \cdot 0$ & $97-113$ & $106 \cdot 5$ & $98-116$ & $96 \cdot 5$ & $90-106$ & $<0.001$ & $\begin{array}{l}\text { (1) } v .(2) \\
(1) v .(3) \\
\text { (2) } v .(3)\end{array}$ & $\begin{array}{r}0.497 \\
<0.001 \\
<0.001\end{array}$ \\
\hline
\end{tabular}

ARV, antiretroviral; IQR, interquartile range; SES, socio-economic status; ND, not determined; NA, not applicable.

Data are presented as median and interquartile range unless otherwise indicated.

${ }^{\star}$ Multiple regression analysis adjusted for age, $P<0.05$ indicates significance.

tKruskal-Wallis test, $P<0.05$ indicates significance.

$\neq \chi^{2}$ test, $P<0.05$ indicates significance. 
Table 2 Body composition variables according to study group: premenopausal black women, Soweto, Johannesburg, South Africa

\begin{tabular}{|c|c|c|c|c|c|c|c|c|c|}
\hline \multirow[b]{2}{*}{ DXA (n 245) } & \multicolumn{2}{|c|}{$\begin{array}{c}\mathrm{HIV}^{-}(n 97) \\
\quad(1)\end{array}$} & \multicolumn{2}{|c|}{$\begin{array}{c}\mathrm{HIV}^{+} \text {non-ARV }(n 74) \\
(2)\end{array}$} & \multicolumn{2}{|c|}{$\begin{array}{c}\mathrm{HIV}^{+} \text {pre-ARV }(n 74) \\
\text { (3) }\end{array}$} & \multirow[b]{2}{*}{$P^{\star}, \mathrm{HIV}^{-}$v. $\mathrm{HIV}^{+}$} & \multirow{2}{*}{$\begin{array}{l}\text { Between-group } \\
\text { comparison }\end{array}$} & \multirow[b]{2}{*}{$P^{*}$} \\
\hline & Median & IQR & Median & IQR & Median & IQR & & & \\
\hline WBLH fat mass $(\mathrm{kg})$ & $24 \cdot 45$ & $17 \cdot 35-30 \cdot 57$ & $25 \cdot 31$ & $18 \cdot 06-32 \cdot 88$ & $18 \cdot 43$ & $12 \cdot 45-25 \cdot 32$ & 0.002 & $\begin{array}{l}\text { (1) } v \cdot(2) \\
\text { (1) } v \cdot(3) \\
\text { (2) } v .(3)\end{array}$ & $\begin{array}{r}0.458 \\
<0.001 \\
<0.001\end{array}$ \\
\hline WBLH lean mass $(\mathrm{kg})$ & $37 \cdot 68$ & $34 \cdot 21-41 \cdot 28$ & $39 \cdot 67$ & $34 \cdot 86-42 \cdot 26$ & $36 \cdot 18$ & $33 \cdot 56-39 \cdot 84$ & $0 \cdot 201$ & $\begin{array}{l}\text { (1) } v .(2) \\
\text { (1) } v .(3) \\
\text { (2) } v .(3)\end{array}$ & $\begin{array}{l}0.512 \\
0.005 \\
0.001\end{array}$ \\
\hline Percentage body fat & $39 \cdot 55$ & $34 \cdot 07-43 \cdot 22$ & $39 \cdot 50$ & $33 \cdot 06-44 \cdot 67$ & $32 \cdot 24$ & $26 \cdot 79-41 \cdot 21$ & $<0.001$ & $\begin{array}{l}\text { (1) } v .(2) \\
\text { (1) } v .(3) \\
\text { (2) } v .(3)\end{array}$ & $\begin{array}{r}0.372 \\
<0.001 \\
<0.001\end{array}$ \\
\hline Fat mass:lean mass ${ }^{2}\left(\mathrm{~kg} / \mathrm{kg}^{2}\right)$ & $17 \cdot 19$ & $13 \cdot 76-20 \cdot 38$ & $15 \cdot 92$ & $13 \cdot 36-19 \cdot 85$ & $13 \cdot 84$ & $10 \cdot 15-18 \cdot 88$ & $<0.003$ & $\begin{array}{l}\text { (1) } v .(2) \\
\text { (1) } v .(3) \\
\text { (2) } v .(3)\end{array}$ & $\begin{array}{c}0.181 \\
<0.001 \\
0.021 \dagger\end{array}$ \\
\hline Trunk fat mass $(\mathrm{kg})$ & $9 \cdot 72$ & $6 \cdot 68-13 \cdot 56$ & $11 \cdot 38$ & $7 \cdot 39-15 \cdot 28$ & $7 \cdot 48$ & $4 \cdot 64-11 \cdot 81$ & 0.007 & $\begin{array}{l}\text { (1) v. (2) } \\
\text { (1) v. (3) } \\
\text { (2) v. (3) }\end{array}$ & $\begin{array}{r}0.592 \\
<0.001 \\
<0.001\end{array}$ \\
\hline Percentage trunk fat & $41 \cdot 56$ & $37 \cdot 67-45 \cdot 65$ & $42 \cdot 85$ & $38 \cdot 54-46 \cdot 38$ & $40 \cdot 92$ & $35 \cdot 75-47 \cdot 07$ & $0 \cdot 717$ & $\begin{array}{l}\text { (1) } v .(2) \\
\text { (1) } v .(3) \\
\text { (2) } v .(3)\end{array}$ & $\begin{array}{l}0.602 \\
0.259 \\
0.117\end{array}$ \\
\hline Limb fat mass $(\mathrm{kg})$ & $14 \cdot 00$ & $10 \cdot 32-16 \cdot 70$ & $13 \cdot 97$ & $10 \cdot 74-17 \cdot 93$ & $10 \cdot 75$ & $7 \cdot 32-14 \cdot 15$ & $<0.001$ & $\begin{array}{l}\text { (1) v. (2) } \\
\text { (1) v. (3) } \\
\text { (2) v. (3) }\end{array}$ & $\begin{array}{r}0.375 \\
<0.001 \\
<0.001\end{array}$ \\
\hline Percentage limb fat & $58 \cdot 44$ & $54 \cdot 35-62 \cdot 33$ & $57 \cdot 15$ & $53 \cdot 62-61 \cdot 46$ & $59 \cdot 08$ & $52 \cdot 93-64 \cdot 25$ & $0 \cdot 717$ & $\begin{array}{l}\text { (1) v. (2) } \\
\text { (1) v. (3) } \\
\text { (2) v. (3) }\end{array}$ & $\begin{array}{l}0.602 \\
0.259 \\
0.117\end{array}$ \\
\hline Trunk:limb fat mass & $0 \cdot 71$ & $0 \cdot 60-0 \cdot 84$ & $0 \cdot 75$ & $0 \cdot 63-0.86$ & $0 \cdot 69$ & $0.56-0.89$ & 0.907 & $\begin{array}{l}\text { (1) } v .(2) \\
\text { (1) } v .(3) \\
\text { (2) } v .(3)\end{array}$ & $\begin{array}{l}0.567 \\
0.445 \\
0.204\end{array}$ \\
\hline
\end{tabular}

DXA, dual energy X-ray absorptiometry; ARV, antiretroviral; IQR, interquartile range, WBLH, whole body less head.

*Multiple regression analysis adjusted for age, $P<0.05$ indicates significance.

tNon-significant due to Bonferroni adjustment. 
Table 3 Multiple regression analyses for BMI, WBLH fat mass, WBLH lean mass, trunk fat mass and limb fat mass: premenopausal black women, Soweto, Johannesburg, South Africa

\begin{tabular}{|c|c|c|c|c|c|}
\hline & $\beta$ & $95 \% \mathrm{Cl}$ & $P$ & & \\
\hline \multicolumn{6}{|l|}{ BMI $\left(\mathrm{kg} / \mathrm{m}^{2}\right)$} \\
\hline Age & $0 \cdot 257$ & $0 \cdot 146,0 \cdot 367$ & $<0.001$ & & \\
\hline $\mathrm{HIV}^{-}$(ref.) & 0 & - & & $R^{2}$ & $0 \cdot 14$ \\
\hline $\mathrm{HIV}^{+}$non-ARV & -0.691 & $-2 \cdot 610,1 \cdot 227$ & 0.479 & Adjusted $R^{2}$ & $0 \cdot 13$ \\
\hline $\mathrm{HIV}^{+}$pre-ARV & $-4 \cdot 487$ & $-6 \cdot 394,-2 \cdot 575$ & $<0.001$ & $P$ & $<0.001$ \\
\hline \multicolumn{6}{|c|}{ WBLH fat mass $(\mathrm{kg})$} \\
\hline Age & 0.347 & $0 \cdot 166,0 \cdot 527$ & $<0.001$ & & \\
\hline $\mathrm{HIV}^{-}$(ref.) & 0 & - & & $R^{2}$ & 0.137 \\
\hline $\mathrm{HIV}^{+}$non-ARV & $-1 \cdot 614$ & $-4 \cdot 767,1 \cdot 539$ & $0 \cdot 314$ & Adjusted $R^{2}$ & 0.123 \\
\hline $\mathrm{HIV}^{+}$pre-ARV & $-7 \cdot 884$ & $-11 \cdot 014,-4 \cdot 753$ & $<0.001$ & $P$ & $<0.001$ \\
\hline \multicolumn{6}{|c|}{ WBLH lean mass $(\mathrm{kg})$} \\
\hline Age & $0 \cdot 214$ & $0 \cdot 128,0 \cdot 300$ & $<0.001$ & & \\
\hline Height & $50 \cdot 826$ & $40 \cdot 207,61 \cdot 445$ & $<0.001$ & & \\
\hline $\mathrm{HIV}^{-}$(ref.) & 0 & - & & $R^{2}$ & 0.342 \\
\hline $\mathrm{HIV}^{+}$non-ARV & -0.439 & $-1 \cdot 949,1 \cdot 070$ & 0.567 & Adjusted $R^{2}$ & $0 \cdot 331$ \\
\hline $\mathrm{HIV}^{+}$pre-ARV & $-3 \cdot 411$ & $-4.910,-1.912$ & $<0.001$ & $P$ & $<0.001$ \\
\hline \multicolumn{6}{|l|}{ Trunk fat mass $(\mathrm{kg})$} \\
\hline Age & $0 \cdot 208$ & $0 \cdot 116,0 \cdot 300$ & $<0.001$ & & \\
\hline $\mathrm{HIV}^{-}$(ref.) & 0 & - & & $R^{2}$ & $0 \cdot 134$ \\
\hline $\mathrm{HIV}^{+}$non-ARV & -0.621 & $-2 \cdot 232,0 \cdot 990$ & 0.448 & Adjusted $R^{2}$ & $0 \cdot 12$ \\
\hline $\mathrm{HIV}^{+}$pre-ARV & $-3 \cdot 521$ & $-5 \cdot 121,-1 \cdot 921$ & $<0.001$ & $P$ & $<0.001$ \\
\hline \multicolumn{6}{|l|}{ Limb fat mass $(\mathrm{kg})$} \\
\hline Age & $0 \cdot 139$ & $0.043,0.234$ & 0.004 & & \\
\hline Height & $12 \cdot 128$ & $0 \cdot 417,23 \cdot 84$ & 0.042 & & \\
\hline $\mathrm{HIV}^{-}$(ref.) & 0 & - & & $R^{2}$ & $0 \cdot 129$ \\
\hline $\mathrm{HIV}^{+}$non-ARV & 0.993 & $-2 \cdot 658,0 \cdot 672$ & 0.241 & Adjusted $R^{2}$ & $0 \cdot 114$ \\
\hline $\mathrm{HIV}^{+}$pre-ARV & $-4 \cdot 362$ & $-6 \cdot 016,-2 \cdot 710$ & $<0.001$ & $P$ & $<0.001$ \\
\hline
\end{tabular}

WBLH, whole body less head; ref., reference category; ARV, antiretroviral.

All variables included in the above models were those which showed significance in prior analyses, $P<0.05$.

battered fried chicken). In addition, fish did not feature in the top twenty food items. Use of fats and oils was very common, with brick/hard margarine and sunflower oil being the regularly reported products $(13 \mathrm{~g} / \mathrm{d}$ and $6 \mathrm{~g} / \mathrm{d}$, respectively). Condiments, high in fat and/or sugar, were regularly added to meals and snacks, with both atchar (a spicy condiment of mangoes and honey, $19 \mathrm{~g} / \mathrm{d}$ ) and tomato sauce $(10 \mathrm{~g} / \mathrm{d})$ featuring in the top twenty food items consumed.

\section{Discussion}

In this sample of black, urban, SA women, HIV-positive individuals had lower weight and BMI, as well as lower fat and lean masses and percentage body fat, than their HIVnegative counterparts. This was primarily as a result of the HIV-positive individuals with low CD4 counts having low measures. Multiple regression analyses showed that $\mathrm{HIV}^{+}$ pre-ARV status, but not $\mathrm{HIV}^{+}$non-ARV status, was a key contributor to differences in WBLH fat mass and WBLH lean mass, as well as both trunk and limb fat masses; associated with $8 \mathrm{~kg}$ and $3 \mathrm{~kg}$ less fat and lean mass, respectively, as well as $3.5 \mathrm{~kg}$ less trunk fat and $4 \mathrm{~kg}$ less limb fat. This challenges the stereotypical view of HIV as a disease associated with involuntary weight loss and wasting prior to ARV initiation and suggests that weight loss may only become a symptom in this population at more severe disease states.
Although WBLH fat mass, as well as trunk and limb fat masses, were lower in the $\mathrm{HIV}^{+}$pre-ARV group than the other study groups, there were no differences in relative terms (trunk and limb fat percentages) across all groups. This, together with the similarity found in trunk:limb fat mass between study groups, suggests lower body fat across all sites rather than an altered fat distribution with advanced HIV infection. This contradicts previous US data which showed an increase in both percentage trunk fat and trunk:limb fat and a decrease in peripheral fat independent of ARV treatment in HIV-positive women compared with HIV-negative controls ${ }^{(13)}$. In addition, it suggests a different pattern of fat loss than that associated with ARV treatment, where lipodystrophy is characterised by abdominal fat accumulation and subcutaneous fat loss, predominantly at the face, limbs and buttocks ${ }^{(30)}$. This is speculative, however, and a longitudinal study is currently being undertaken in this population which it is hoped will provide more definitive answers.

As previously documented by Hamill et al. ${ }^{(20)}$, the $\mathrm{HIV}^{+}$pre-ARV group had a lower fat mass:lean mass ${ }^{2}$ than the other two study groups, demonstrating approximately $21 \%$ and $16 \%$ less fat for each kilogram of lean mass than the $\mathrm{HIV}^{-}$and $\mathrm{HIV}^{+}$non-ARV groups, respectively. This provides evidence of lower fat mass, rather than lean tissue, at more advanced stages of HIV infection. Although previous literature has found HIV to be associated with preferential loss of lean compared 
with fat tissue, particularly in male subjects, a disproportionately higher loss of fat mass has been shown in US women ${ }^{(31)}$. In addition, a preferential loss of fat rather than lean tissue mass has been demonstrated in males with high body fat percentages at baseline, compared with those having less than $15 \%$ body fat ${ }^{(32)}$.

Overweight and obesity were common in the sample overall, with a combined prevalence of $59 \%$, a prevalence higher than the national estimate of $55 \%$ reported for black women in the 2003 SADHS $^{(4)}$. Although the distribution of women across BMI cut-offs differed significantly between the $\mathrm{HIV}^{+}$pre-ARV group and the other two study groups, there was still a $44 \%$ prevalence of overweight and obesity in this group, while another $11 \%$ were classified as underweight. Even at more advanced stages of HIV infection, women are affected by obesity and this needs to be addressed in the population as a whole.

There were no reported differences in dietary intake across study groups, with the exception of total and animal protein intakes which were lower in the $\mathrm{HIV}^{-}$group than in the $\mathrm{HIV}^{+}$groups combined. However, when adjusted for age and total energy intake, these differences were no longer significant. There was no relationship between protein intake and SES $(P=0 \cdot 202)$. These results also highlight that all groups, including the pre-ARV therapy group with lower median BMI, consume an obesogenic diet. Given the high levels of inflammation and high carbohydrate intake, these participants are likely to have a high prevalence of insulin resistance and other metabolic abnormalities. These are areas for potential future research.

Food item and food group analyses showed similar consistency of consumption across the groups, regardless of HIV status. The main contributor to the variation in food mass consumed between the three groups seemed to be 'pap' (maize meal porridge), which differed by approximately $135 \mathrm{~g} / \mathrm{d}$ between the $\mathrm{HIV}^{+}$pre-ARV group and the HIV group and approximately $92 \mathrm{~g} / \mathrm{d}$ between the $\mathrm{HIV}^{+}$pre-ARV group and the $\mathrm{HIV}^{+}$non-ARV group. Diets in the sample as a whole were very high in refined carbohydrate, which is reflected by the high total digestible carbohydrate intake (approximately three-fold higher than the RDA of $130 \mathrm{~g} / \mathrm{d}$ ). Consumption of processed and fast-food products was common and that of fruits and vegetables rare, with the vegetable items consumed (e.g. tomato and onion stew) usually containing added sugar and/or fat. In addition to added sugar intakes, high sugar-based products were also common; with carbonated soft drinks featuring second in the top twenty food items consumed. This is a concern due to the link seen between sugar-sweetened beverage intake and weight gain, as well as diabetes and CVD risk ${ }^{(33,34)}$. The lack of fish, and therefore $n$-3 PUFA, in the top twenty reported food items should also be addressed due to the important role that these essential fatty acids have in regulating immune function ${ }^{(35)}$. The highly processed nature of food products, as well as high sugar and fat and 
Table 5 Top twenty food items consumed in the sample of premenopausal black women, Soweto, Johannesburg, South Africa

\begin{tabular}{lllr}
\hline & Food item & Food group* & Mean intake (g/d) \\
\hline 1. & Maize meal porridge (cooked stiff/'pap') & Cereal and cereal products & 258 \\
2. & Carbonated cold drink (e.g. Coca Cola) & Sugar, syrups and sweets & 197 \\
3. & Brown bread/rolls & Cereal and cereal products & 121 \\
4. & Full fat milk & Milk and milk products & 84 \\
5. & White bread/rolls & Cereal and cereal products & 69 \\
6. & White rice & Cereal and cereal products & 72 \\
7. & Banana & Fruit & 53 \\
8. & Apple & Fruit & 46 \\
9. & French fries & Vegetables & 34 \\
10. & Tomato and onion (stewed) & Vegetables & 22 \\
11. & Chicken, dark meat (fried/roasted) & Meat and meat products & 20 \\
12. & Atchar (mango and honey) & Sauces, seasonings and flavourings & 19 \\
13. & Granulated white sugar & Sugar, syrups and sweets & 15 \\
14. & Brick/hard margarine & Fats and oils & 13 \\
15. & Tomato sauce & Sauces, seasonings and flavourings \\
16. & Batter dipped fried chicken (e.g. KFC) & Meat and meat products & 9 \\
17. & Cheddar cheese & Milk and milk products & 7 \\
18. & Polony & Meat and meat products & 6 \\
19. & Sweets (hard boiled/soft jelly type) & Sugar, syrups and sweets & 6 \\
20. & Sunflower oil & Fats and oils \\
\hline
\end{tabular}

${ }^{\star}$ Food items grouped according to the current South African Medical Research Council food composition tables ${ }^{(37)}$.

low vegetable consumption in the sample is an important health issue and highlights the urgent need to address obesity and its risk factors throughout the population.

Although providing an overall picture of habitual energy and macronutrient intakes, as well as of commonly consumed food items, the dietary data had certain limitations. The proportion of women classified as 'underreporters' was very high ( $31 \%$, data not shown), suggesting that a substantial number were underestimating their consumption. This may have been due to the high prevalence of overweight and obesity in the sample, as high BMI has previously been shown to predict underreporting ${ }^{(36)}$. Due to the negative impact that excluding these participants would have had on sample size, truncation was therefore chosen as the best possible method of minimising the effects of under-reporting on study results. Classification of food items based on the SA food composition table was also flawed as it misclassified items such as French fries into the vegetable group, thereby overestimating vegetable consumption in the sample. This classification should be revised in the future to ensure that vegetables high in starch with added fat are more accurately categorised.

A key limitation of the study was that the participants were not a random sample of the adult female population of Soweto and the surrounding area, as inclusion in the study required the women to present at the Chris Hani Baragwanath Hospital's Perinatal HIV Research Unit, HIV clinic, or voluntary counselling and testing centre. Women must, therefore, both know that the services exist and have access to them, must be healthy enough to present at the hospital, and must have sufficient information on HIV and its risks to be motivated to seek counselling or care. This could mean that the HIV-posi- tive and HIV-negative participants included in the study are not a truly representative sample and may also have better knowledge of poor dietary practices and other health risks than the wider population.

Regardless of these weaknesses, the present paper provides unique data on diet and body composition differences between HIV-negative and HIV-positive women at varying levels of immunosuppression prior to treatment. In addition, the longitudinal design of the broader study will allow for future analysis of the changes in anthropometric, body composition and dietary variables in this population at 6 months, 12 months and 24 months follow-up.

\section{Conclusion}

Our data show that immunosuppression may be a predictor of anthropometric and body composition changes in HIV-positive women and that, in populations with high obesity prevalence, these differences become evident only at advanced stages of infection. This highlights the need for a change in the way diet and body composition are viewed in HIV-positive patients, while emphasising that poor dietary habits should be addressed in the SA female, urban population as a whole.

\section{Acknowledgements}

Sources of funding: This work was supported by the UK Medical Research Council (programme grant number U105960371) and by an MRC PhD Clinical Research Training Fellowship (MC_EX_G1001958 to M.M.H.). Conflicts of interest: All authors report no conflicts of 
interest. Authors' contributions: The study was designed by M.M.H. and A.P. and the study design was reviewed by M.M.H., J.M.P., S.A.N. and A.P. S.V.W. and A.B.F. analysed the data. The initial phase of data analysis was conducted as part of S.V.W.'s MSc research project at the London School of Hygiene and Tropical Medicine. All authors contributed to interpretation and the writing of the manuscript. All authors had full access to the data. S.A.N. had responsibility for the final decision to submit the manuscript for publication. Acknowledgements: The authors wish to acknowledge all of the study participants and staff at the Developmental Pathways for Health Research Unit, ZAZI/Perinatal HIV Research Unit, Nthabiseng and Lilian Ngoyi clinics, Johannesburg, South Africa.

\section{References}

1. Crum-Cianflone N, Roediger MP, Eberly L et al. (2010) Increasing rates of obesity among HIV-infected persons during the HIV epidemic. PLoS One 5, e10106.

2. Tate T, Willig AL, Willig JH et al. (2012) HIV infection and obesity: where did all the wasting go? Antivir Ther 17, 1281-1289.

3. Joint United Nations Programme on HIV/AIDS (2010) UNAIDS Report on the Global AIDS Epidemic 2009. Geneva: UNAIDS.

4. Department of Health, Medical Research Council \& ORC Macro (2007) South Africa Demographic and Health Survey 2003. Pretoria: Department of Health.

5. Crum-Cianflone N, Tejidor R, Medina S et al. (2008) Obesity among patients with HIV: the latest epidemic. AIDS Patient Care STDS 22, 925-930.

6. Ferrando SJ, Rabkin JG, Lin SH et al. (2005) Increase in body cell mass and decrease in wasting are associated with increasing potency of antiretroviral therapy for HIV infection. AIDS Patient Care STDS 19, 216-223.

7. Mallon PW, Miller J, Cooper DA et al. (2003) Prospective evaluation of the effects of antiretroviral therapy on body composition in HIV-1-infected men starting therapy. AIDS 17, 971-979.

8. Mwamburi DM, Wilson IB, Jacobson DL et al. (2005) Understanding the role of HIV load in determining weight change in the era of highly active antiretroviral therapy. Clin Infect Dis 40, 167-173.

9. Dave JA, Lambert EV, Badri M et al. (2011) Effect of nonnucleoside reverse transcriptase inhibitor-based antiretroviral therapy on dysglycemia and insulin sensitivity in South African HIV-infected patients. J Acquir Immune Defic Syndr 57, 284-289.

10. Esposito F, Coutsoudis A, Visser J et al. (2008) Changes in body composition and other anthropometric measures of female subjects on highly active antiretroviral therapy (HAART): a pilot study in KwaZulu-Natal, South Africa. Southern Afr J HIV Med 9, 36-42.

11. Mercier S, Gueye NF, Cournil A et al. (2009) Lipodystrophy and metabolic disorders in HIV-1-infected adults on 4- to 9-year antiretroviral therapy in Senegal: a case-control study. J Acquir Immune Defic Syndr 51, 224-230.

12. Despres JP (2007) Cardiovascular disease under the influence of excess visceral fat. Crit Pathw Cardiol 6, 51-59.

13. Hadigan C, Miller K, Corcoran C et al. (1999) Fasting hyperinsulinemia and changes in regional body composition in human immunodeficiency virus-infected women. J Clin Endocrinol Metab 84, 1932-1937.
14. George JA, Venter WD, Van Deventer HE et al. (2009) A longitudinal study of the changes in body fat and metabolic parameters in a South African population of HIV-positive patients receiving an antiretroviral therapeutic regimen containing stavudine. AIDS Res Hum Retroviruses 25, $771-781$.

15. Macallan DC, Noble C, Baldwin C et al. (1995) Energy expenditure and wasting in human immunodeficiency virus infection. $N$ Engl J Med 333, 83-88.

16. Hattingh Z, Walsh CM, Veldman FJ et al. (2006) Macronutrient intake of HIV-seropositive women in Mangaung, South Africa. Nutr Res 26, 53-58.

17. Arendt BM, Aghdassi E, Mohammed SS et al. (2008) Dietary intake and physical activity in a Canadian population sample of male patients with HIV infection and metabolic abnormalities. Curr HIV Res 6, 82-90.

18. Duran AC, Almeida LB, Segurado AA et al. (2008) Diet quality of persons living with HIV/AIDS on highly active antiretroviral therapy. J Hum Nutr Diet 21, 346-350.

19. Hendricks KM, Willis K, Houser R et al. (2006) Obesity in HIV-infection: dietary correlates. J Am Coll Nutr 25, 321-331.

20. Hamill M, Ward K, Pettifor J et al. (2013) Bone mass, body composition and vitamin D status of ARV-naïve, urban, black South African women with HIV infection, stratified by CD 4 count. Osteoporos Int (Epublication ahead of print version).

21. Nel J \& Steyn JP (2002) Report on South African Food Consumption Studies Undertaken among Different Population Groups (1983-2000): Average Intakes of Foods Most Commonly Consumed. Pretoria: Department of Health.

22. Zingoni C, Norris SA, Griffiths PL et al. (2009) Studying a population undergoing nutrition transition: a practical case study of dietary assessment in urban South African adolescents. Ecol Food Nutr 48, 178-198.

23. Steyn N \& Senekal M (2005) A Guide for the Use of the Dietary Assessment and Education Kit (DAEK). Cape Town: Medical Research Council.

24. Steyn NP, Senekal M, Norris SA et al. (2006) How well do adolescents determine portion sizes of foods and beverages? Asia Pac J Clin Nutr 15, 35-42.

25. Langenhoven ML, Kruger M, Gouws E et al. (1991) MRC Food Composition Tables, 3rd ed. Cape Town: Medical Research Council.

26. Goldberg GR, Black AE, Jebb SA et al. (1991) Critical evaluation of energy intake data using fundamental principles of energy physiology: 1. Derivation of cut-off limits to identify under-recording. Eur J Clin Nutr $\mathbf{4 5}$, $569-581$

27. Black AE (2000) Critical evaluation of energy intake using the Goldberg cut-off for energy intake:basal metabolic rate. A practical guide to its calculation, use and limitations. Int J Obes Relat Metab Disord 24, 1119-1130.

28. Food and Nutrition Board, Institute of Medicine (2002) Dietary Reference Intakes for Energy, Carbohydrate, Fiber, Fat, Fatty Acids, Cholesterol, Protein, and Amino Acids. Washington, DC: The National Academies Press.

29. McVeigh JA, Norris SA \& de Wet T (2004) The relationship between socio-economic status and physical activity patterns in South African children. Acta Paediatr 93, 982-988.

30. James J, Carruthers A \& Carruthers J (2002) HIV-associated facial lipoatrophy. Dermatol Surg 28, 979-986.

31. Grinspoon S, Corcoran C, Miller K et al. (1997) Body composition and endocrine function in women with acquired immunodeficiency syndrome wasting. J Clin Endocrinol Metab 82, 1332-1337.

32. Mulligan K, Tai VW \& Schambelan M (1997) Cross-sectional and longitudinal evaluation of body composition in men 
with HIV infection. J Acquir Immune Defic Syndr Hum Retrovirol 15, 43-48.

33. Hu FB \& Malik VS (2010) Sugar-sweetened beverages and risk of obesity and type 2 diabetes: epidemiologic evidence. Physiol Behav 100, 47-54.

34. Malik VS, Popkin BM, Bray GA et al. (2010) Sugarsweetened beverages, obesity, type 2 diabetes mellitus, and cardiovascular disease risk. Circulation 121, 1356-1364
35. Calder PC \& Yaqoob P (2009) Omega-3 polyunsaturated fatty acids and human health outcomes. Biofactors 35, 266-272.

36. Price GM, Paul AA, Cole TJ et al. (1997) Characteristics of the low-energy reporters in a longitudinal national dietary survey. Br J Nutr 77, 833-851.

37. Wolmarans P, Danster N, Dalton A et al. (editors) (2010) Condensed Food Composition Tables for South Africa. Cape Town: Medical Research Council. 